\title{
The moral significance of spontaneous abortion
}

\author{
Timothy F Murphy Department of Philosophy, Boston University, Boston, USA
}

\section{Author's abstract}

Spontaneous abortion is rarely addressed in moral evaluations of abortion. Indeed, 'abortion' is virtually always taken to mean only induced abortion. After a brief review of medical aspects of spontaneous abortion, $I$ attempt to articulate the moral implications of spontaneous abortion for the two poles of the abortion debate, the strong pro-abortion and the strong anti-abortion positions. I claim that spontaneous abortion has no moral relevance for strict pro-abortion positions but that the high incidence of spontaneous abortion is not (as some claim) eo ipso any sort of justification for voluntarily induced abortion. Secondly, I show that if the strict anti-abortionist position is to be taken seriously in its insistence that prenatal life has a right to be protected by virtue of its being conceived, then it seems necessary to take measures to prevent spontaneous abortion and its presumptive causes, and this as a matter of moral obligation.

\section{Introduction}

The literature on the morality of abortion is extensive, and the conflict surrounding the theory and practice of abortion shows little sign of abating. Public figures and private citizens, philosophers and theologians, sociologists and medical doctors continue to address themselves to the various phenomena that make up the moral issues surrounding abortion.

In discussions of abortion, the term is virtually always taken to be synonymous with 'induced abortion', ie, abortion wilfully undertaken for the express purpose of ending a pregnancy (for whatever reason). Even comprehensive surveys of abortion take no notice of the phenomenon of spontaneous abortion, that is, termination of the pregnancy independent of the woman's will or, as we shall see, even independent of her knowledge (1).

In this essay, I want to address myself to the issue of spontaneous abortion. First, I will present a short medical account of spontaneous abortion. In light of that information on the terminology, incidence,

\section{Key words}

Anti-abortion; conception; induced abortion; pro-abortion; spontaneous abortion. aetiology, and treatment of spontaneous abortion, $\mathrm{I}_{\overline{\mathbb{N}}}$ will examine how spontaneous abortion might be seen by anti-abortionists and pro-abortionists. It will $\mathrm{be}_{\tilde{\mathrm{N}}}^{\overrightarrow{\mathrm{N}}}$ seen that the facts of spontaneous abortion pose seriousquestions for strict anti-abortionists, but seem to have $e^{6}$ little import for strict pro-abortionists. It will be seen? though that the high incidence of spontaneous abortion $\vec{C}_{\vec{C}}$ is not by itself any kind of argument on behalf of induced abortion, as has been claimed by pro- ${ }^{\infty}$ abortionists. At any rate, 'abortion' should not be $\vec{\oplus}$ equated with voluntarily induced abortion. It is alsoor important that spontaneous abortion is not presumedo to be without moral relevance.

\section{Medical background}

In this section, for basic information on the terminology, incidence, aetiology, and treatment of $\overrightarrow{\overrightarrow{0}}$ spontaneous abortion, I rely on Williams Obstetrics, 16 th edition (2), widely referenced in the United States.

Terminology: 'Abortion is the termination of $\overline{\overline{3}}$ pregnancy by any means before the fetus is sufficiently. developed to survive.' Spontaneous abortion or 3 . miscarriage occurs without inducement by the mother or other persons. Typically, the abortus is grossly defective or dead.

The medical categories of spontaneous abortion are? these: (a) threatened abortion: common symptom is bloody discharge in early pregnancy; (b) inevitable abortion: abortion invariably follows rupture of membranes and cervical dilation; (c) incompleter abortion: characterised by partial expulsion of fetus and/or placenta; (d) missed abortion: characterised by prolonged retention of the dead fetus.

Incidence: It had generally been believed that thes incidence of spontaneous abortion was about ten peros? cent of all pregnancies. Some researchers report; however, that the mean incidence of spontaneouso abortion for all known pregnancies is 15 per cent. A any rate, it is not uncommon.

On the other hand, it is important to notice tha these figures refer to known pregnancies. Spontaneous abortion may not even be recognised, the product of union between sperm and egg being aborted ac menstruation without the woman's being aware oto 
being able to be aware that abortion has in fact occurred. Moreover, this kind of abortion may constitute the largest category of any kind of abortion: 'Roberts and Lowe (1975) have provided cogent arguments to support their hypothesis that at least three fourths of very early pregnancies are aborted spontaneously, although most of the time the state of pregnancy is never identified' (3). Other researchers have challenged these figures, but the incidence of unrecognised spontaneous abortion is still acknowledged as quite high.

Aetiology: The causes of spontaneous abortion are a matter of continuing investigation. Several observations are a matter of general agreement. In early months, spontaneous expulsions nearly always are preceded by the death of the embryo or fetus. The fetus is not usually dead in late spontaneous abortion. Fetal death may be caused by abnormalities in the ovum itself, abnormalities in the generative tract, or systemic disease of the mother (or perhaps, rarely, the father).

Fifty to sixty per cent of early spontaneous abortions are associated with chromosomal anomaly. Chromosomal abnormalities are more commonly associated with extra or missing chromosomes of the conceptus than with structural failure of the chromosomes. Such abnormality radically affects the development of the embryo, the early fetus, or the placenta. Incidence of this kind of abnormality decreases with gestational age.

Other considerations in the incidence of spontaneous abortion are less well researched but may sometimes be causally linked with its occurrence. Such factors include: physical trauma, increased age of gametes, suboptimal uterine nutrition, radiation, viruses, chemicals, hormonal abnormalities, infectious diseases, incompatible blood groups, anatomical uterine defects, psychiatric causes, incompetent cervix, and previous, multiple, induced abortions (4).

Treatment: Evidence indicates that attempts to prevent threatened abortion by hormones merely delay the abortion. Even when there are 'successful' treatments, the likelihood is that a missed abortion results. Inevitable abortions, as the name indicates, are beyond treatment. Incomplete abortions require removal of remaining fetal or placental tissue. In missed abortions, treatment also involves removal of tissue although one can simply wait for spontaneous abortion.

\section{Moral significance}

The moral significance of spontaneous abortion is best seen by examining it in the light of the major, opposing claims about the morality of induced abortion. I would like to sketch out below how spontaneous abortion assumes significance with respect to (a) strong proabortion claims that abortion is wholly acceptable at any time and (b) strong anti-abortion claims that abortion is never morally legitimate.
A. Strong pro-abortionists do not all hold identical positions. Some hold that fetal life has no protectable rights at any point prior to, for example, viability, birth, attainment of self-consciousness and so forth. Some pro-abortionists deny prenatal life standing as human, as a human being, or as a person. Often these pro-abortionists use a developmental model of personhood whereby personhood (and thereby rights) follow biological or social achievements. Abortion is permissible, therefore, to the extent that one is not killing a person, ie, prior to the attainment of the stated conditions of personhood. Some pro-abortionists on the other hand, go so far as to concede human personhood and a right to life of the fetus and yet still conclude that a woman may legitimately choose to abort since her rights take precedence over those of the fetus (5).

Following the lines of this last argument, abortion at any time, perhaps even infanticide, is morally permissible. This argument presumes the ontological model of personhood that is generally used by antiabortionists, namely that subsequent to conception there is continuous development of a person, ie, at no time is there not a person. The rationale for this strong pro-abortion position makes maternal discretion and maternal rights the essential features of the decision. It is perhaps the strongest kind of pro-abortion argument possible.

In these pro-abortion arguments, one sometimes finds the high incidence of spontaneous abortion used as a justifying rationale for a pro-abortion stance. Roberts and Lowe, for instance, write: 'If Nature resorts to abortion to maintain genetic stability by discarding as many as 3 in every 4 conceptions, it will be difficult for anti-abortionists to oppose abortion on moral and ethical grounds' (6).

One does not have to go very far to show that this claim is too quickly made. In effect, the authors are saying that because there is a high incidence of spontaneous abortion (presumably of genetically abnormal conceptions) induced abortion becomes morally permissible. In short, what is natural, ie, as an event in nature, is taken to establish a moral guideline. It is, however, unacceptable to make this strict identification between events in nature and moral precepts. That there are diseases 'in nature' does not mean that medicine is obliged to forego curing them let alone that it is obliged to induce them! If one is going to appeal to Nature as a foundation for a kind of natural moral law, it is important to realise that moral obligations derive not from any chronicle of observed phenomena in nature but from the concept of human nature, ie, what it is to be human in terms of natural goods and goals. Thus, even if 99 out of every 100 conceptions were to end in spontaneous abortion, one might still want to make the claim that voluntary, induced abortion was wrong because it violated the human goods and goals of, for example, procreation, charity, reverence for life, and so forth.

Even, however, if we were to take the high incidence 
of spontaneous abortion as a moral guideline, it is not clear how its purported preservation of genetic stability would be relevant to situations not involving 'genetic stability', including the majority of induced abortions. The only induced abortions which might be justified by such a putative moral guideline would seem to be those of genetically defective embryos or fetuses. However, further doubt would be cast upon even this limited moral relevance of the natural occurrence of spontaneous abortion by the fact that in nature not all genetically defective fetuses are aborted: many severe genetic defects in pregnancies come to full term.

Thus, to think that because there is a high, even an extremely high incidence of spontaneous abortion of genetically abnormal conceptuses it follows that deliberate abortions are thereby morally unproblematic is (a) to ignore the material difference between willed and unwilled abortions, (b) to misunderstand events in nature as necessarily constituting moral Natural Laws, and (c) to suppose mistakenly that the identification of the 'natural' with the 'moral' could be unambiguous.

Is there though any moral significance of spontaneous abortion for the strong pro-abortionist? For the strong pro-abortionist who considers the products of conception as only so much tissue (or even, in some cases, a person) retainable or not at the woman's discretion, it would seem that the fact of spontaneous abortion is neither morally problematic nor morally enlightening. After all, if intentional induction of abortion is not objectionable, then it hardly seems to follow that anyone has an obligation to a spontaneously aborted fetus, any more than one has to hair which falls out of its own accord. Of course, the context of the spontaneous abortion may be of some moral concern, whether it involves grief at the loss of a desired pregnancy or relief, perhaps resolution of a dilemma, at the loss of an undesired pregnancy.

B. The anti-abortion case is often grounded in the argument that abortion kills innocent persons. Consequently, abortion is taken to be a grave moral offence justified only in the rarest of circumstances, and even then it must never be directly intended. Antiabortion arguments are often accompanied by theological or biological considerations, but in the main the basic claim seems to be an ontological one: a person comes into existence at conception. Personhood establishes a right to life, a right not to be aborted, and establishes the corresponding duty on our part to sustain, nurture, and protect those rights. As against developmental models of persons, on this model, a person can only come from that which is a person. Hence, there is from conception onward nothing but development of a person (as against development to a person), a person with protectable rights. Because these rights are established not on the basis of one's social standing or one's biological capacities, but are intrinsic, they are not to be overridden by, for example, a woman's expression of her rights. As was the case with pro-abortionism, there are other kinds of rationales which might lead to an anti-abortion conclusion, but I think that this ontological model is probably the strongest kind of anti-abortion groundwork.

The question to be addressed in the light of this argument is whether or not conceptions (while still alive) threatened by spontaneous abortion have the same entitlement to protection that the antiabortionists claims for life at risk of induced abortion.

One Catholic ethicist discusses the topic of spontaneous abortion but does so from the point of view of the mother's and doctor's obligation in the case of threatened abortion. T J O'Donnell's pervasive premise is that qua conceived there is a right to be sustained as far as possible. What is the mother's obligation in the case of threatened abortion? He says: 'The moralist's answer to this question is based on the principles of charity, reinforced by the mother-child i relationship. The infant is in extreme physical danger and therefore the mother is obliged to undergo very serious hardship as long as there is real hope of saving the infant' (7). The primacy of obligation to fetal life is affirmed here, even in the likelihood of imminent abortion. O'Donnell cautions that it is hard to tell when a threatened abortion becomes inevitable. The decision for treatment of the mother should be left to the judgement, he says, of the competent and conscientious obstetrician since spontaneous abortion mostly occurs as the result of pathological incapacity for continuing pregnancy. That is, these spontaneous abortions represent already interrupted pregnancies (8). The justification for any hastening of fetal death in the case of inevitable abortion comes under the exculpatory principle of double effect; in the treatment of the mother, fetal death is neither intended directly nor likely to be materially influenced by the treatment. When, however, the obstetrician is unsure about complete placental separation (and hence unsure about the inevitability of the abortion), then accelerated abortion is totally unjustifiable (9).

O'Donnell's articulation of issues here is consistent with a strong anti-abortion position. Yet he deals only $\mathrm{O}$ with spontaneous abortions that are recognised. $\frac{D}{2}$ Indeed, many of the situations that he describes involve relatively late miscarriages. Yet surely the $N_{0}$ arguments that $O^{\prime}$ Donnell adduces against direct abortion have some relevance to spontaneous abortion: is a conceptus spontaneously aborted (while it still $\omega$ lives, no matter how feebly) any less innocent than one deliberately aborted? O'Donnell' says that positions $\stackrel{\circ}{\complement}$ which hold that there is no human being until after $\mathbb{D}$ birth are unacceptable legally, physiologically, philosophically and theologically. It is enough that it is probable that embryonic life is human from the first $\frac{\mathbb{D}}{\mathbb{D}}$ moment of its existence' to render such life exempt $\frac{\rho}{\mathbb{P}}$ from abortion (10). Is this probability enough to make $\stackrel{2}{2}$ it morally obligatory to try and 'exempt' embryonic life from spontaneous abortion?

If the argument of the anti-abortionists hangs on the establishment of a unique individual because of its 
conception, then it seems clear on the face of it, that all conceptions establish lives properly protectable. If so, then it seems to follow that we meet our duty only if we prevent/resist not only induced abortion but spontaneous abortion as well. If we take the antiabortionists seriously on their moral terra firma that conception endows innocent human lives with full human rights, including a right not to be killed and a right to protection in life-threatening situations, then it seems a matter of moral obligation that we protect all human life qua conceived.

This conclusion raises a number of important questions. First of all, conception itself is not immediately detectable presently by the mother or other observer. Implantation is usually suggested as the point at which pregnancy becomes detectable. How then do we meet our obligations with respect to conceptions that, via spontaneous abortion, are sloughed off unawares? Recall that this may be the fate of three-quarters of all fertilised ova. The consistent answer, I suppose, is that it becomes morally obligatory to find ways of detecting conception immediately since it is at that point (according to this argument) that our obligations to prenatal life begin. Any evasion of this responsibility might result in morally culpable negligence of spontaneous abortion.

In order to deny obligation for preventing all spontaneous abortion subsequent to conception, antiabortionists might want to stress its involuntary nature. That is, they might want to argue that no moral responsibility exists since (a) the mother (indeed, anyone) cannot tell for some time whether or not conception has taken place, (b) the genetic composition or state of development of many conceptions destined to abort is perhaps such that no true humanity is present, or even (c) that such spontaneous abortion is the presumable will of God.

Firstly, it seems to me, that such counterarguments are completely beside the point if conception itself is defined as the metaphysical inception of an innocent being endowed with full human rights including a right not to be killed, and a right to be protected in lifethreatening conditions, rights it is our duty to try and sustain. To say that a woman cannot tell whether or not there is a conception does not and cannot negate the innocence or the rights of such a being if these qualities are held to be intrinsic (ie not granted according to development or social decree but endowed by virtue of what a thing is).

Secondly, to say there is in some cases insufficient genetic potentiality introduces the very kind of criterion strong anti-abortionists reject: that there is a point of consciousness, capacity, or whatever which a conceptus must achieve before 'earning' his/her rights. To say that human beings deficient in quality $\mathrm{X}$ are legitimately abortable is to capitulate to the very kind of situational assessment the strong anti-abortionist argument is designed to obviate. One might want to argue that in the case of radically defective conceptuses, conception properly speaking did not occur. This seems dangerous from an anti-abortionist point of view because, again, it introduces biological standards, the very kind of standards that it rejects elsewhere as arbitrary. It seems better to say that conception has taken place, but that it has failed to produce a being that is viable as an embryo or fetus. But even this concession does not seem to establish by itself why the conception's right to life or right to be protected should be taken any less seriously.

Finally, once defined as innocent and endowed with rights by virtue of conception, it also seems theologically dubious to say that the fate of embryonic life rests wholly with deity. Is there another class of beings, who being innocent, human, and endowed with equivalent rights we would abandon altogether and solely to the will of God without even trying to protect their lives? This conclusion would also seem to presume !nequivocal interpretation of God's will or revelation, something theological interpretation does not always lend itself to.

Therefore, it seems that a duty to try to prevent spontaneous abortion for the sake of protecting innocent human life is the conclusion one must draw from the premises of the strong anti-abortionists' argument.

However, this is a problematic conclusion. Medical treatment of spontaneous abortion is severely limited in what it can accomplish. At present, much spontaneous abortion is often not even recognised as such, occurring during regular menstruation. Secondly, treatment methods have ambiguous results. As indicated above, treatment of threatened abortion often merely prolongs the retention of an already dead embryo or fetus. Female fetuses, too, can be 'virilised' by the effects of progestogens used to thwart expulsion (11). On the other hand, in the interests of moral consistency, should not a strong anti-abortionist argue that despite the difficulties of treatment, it should be pursued rather than permitting fetal life to be aborted? Should not the strong anti-abortionist also argue colaterally that medical research is desirable and even morally obligatory in order to establish treatment methods that do not merely delay inevitable expulsion? Should not methods be sought to detect endangering conditions, in both fetus and mother, in order ultimately to sustain the lives of all embryos and fetuses however genetically defective? The only point of release from this litany of obligations would seem to be the death of the embryo or fetus itself, in which case our moral obligations would shift to treatment of the mother (although obligations as to how we treat the dead fetus would still be in force).

As was indicated above, spontaneous abortion may, in some cases, be caused by infectious diseases, physical trauma, and so forth. One could make a case, then, that a woman would have to take into account exposure of fetal life to jeopardising circumstances in order to prevent spontaneous abortion. However, since the relation between infectious diseases and other putative causes of spontaneous abortion is not well 
understood, acceptable behaviour and the extent of any culpability would be very difficult to ascertain. At any rate, should circumstances likely to result in spontaneous abortion be identified, it would seem that a strong anti-abortionist should rightly condemn wilful exposure to those circumstances.

In sum, then, once embryonic and fetal life is defined as innocent and possessed of rights by virtue of its conception, it seems that spontaneous abortion is a very serious matter for strong anti-abortionists. That some products of conception are radically defective does not seem to change the nature of our obligation to such life. It appears to follow for the strong antiabortionist that our moral obligations to prenatal life are even vaster than we had previously imagined, and that anti-abortion politics should no longer confine themselves to induced abortion, since many, maybe the majority, of abortions are spontaneous.

\section{Conclusions}

For the sake of the argument, I have discussed the two poles of the abortion argument, the one pole being the strong pro-abortionist stance and the other being the strong anti-abortion stance. The first kind of argument, by various rationales, maintains the primacy of a woman's rights over any real or imagined rights of any fetal life at any stage of development. The second kind of argument, primarily by claiming that $q u a$ conceived there is innocent, protectable human personhood, maintains that no abortion is ever legitimate. I have attempted to show what moral significance spontaneous abortion, possibly the largest class of abortions, might have for these respective positions.

The incidence and treatment of spontaneous abortion seems to have the most significance for those who would hold that conception immediately confers full human rights. One seems subsequently obliged to try and prevent spontaneous abortions, even those presently undetected, and to find treatment which does not merely end in the retention of dead fetuses. Pratically speaking the salvaging of every conception seems an inordinately difficult task. On the other hand, the theory of anti-abortionism is not overthrown by the mere practical difficulty of the prospective task. Its claims seem to remain intact even as its sphere of duties expands.

For the strong pro-abortionist, spontaneous abortion would seem to have no moral import, since the source of obligation to fetal life is held to follow from considerations other than what kind of being it is. If the pro-abortionist's argument about the legitimacy of wilful abortion is correct, then involuntary abortion is certainly no more problematic. For the strong proabortionist (as with the strong anti-abortionist) the loss of a pregnancy may have meaning such as grief or $\stackrel{\square}{\mathrm{m}}$ relief, but that nature 'wastes' human life is in itself a matter of moral indifference. The high incidence of spontaneous abortion however affords no justification for concluding that voluntary abortion is morally acceptable. Other considerations would have to decideo that issue.

The burden of these conclusions falls on the shoulders of the strong anti-abortionists. Given the $\stackrel{\mathbb{Q}}{\Omega}$ importance of these conclusions, I think it is a serious? mistake to focus the discussion about the morality of ${ }^{e}$ abortion solely on induced abortion. Consideration of $\stackrel{\circ}{\circ}$ spontaneous abortion shows, at the very least, how $\vec{\omega}$ certain anti-abortionist premises become problematic. $\stackrel{\text { }}{\circ}$ If these conclusions are true, then it seems to me that the strong anti-abortionist argument demands much $\stackrel{\Phi}{.}$ more from those who would affirm it than they had $\vec{\overrightarrow{ }}$ hitherto realised.

\section{References and notes}

(1) Just as a sample, I list these widely known sources which do not address themselves to spontaneous abortion. despite their pretensions to comprehensiveness: Jaffe $F, \square$ Lindheim B, Lee P. Abortion politics: private morality and public policy. New York: McGraw-Hill, 1981; Callahan D. Abortion: law, choice and morality. New York: Macmillan, 1970. Nathanson B, Ostling R N. Aborting $\stackrel{\circ}{\Phi}$ America. Garden City, NJ: Doubleday, 1979; Feinberg $\mathrm{J}$, ed. The problem of abortion. (2nd ed) Belmont, CA:음 Wadsworth, 1984; Hellegers A. Abortion, medical 3 aspects. In: Reich W T, ed. Encyclopedia of bioethics. Vol 1. New York: The Free Press, 1978. Anthologies? designed for medical ethics courses show the same lacuna. Journal articles in philosophy and theology by and large never make the spontaneous/induced abortion 0 distinction.

(2) Pritchard J A, MacDonald P C, eds. Williams obstetrics. (16th ed) New York: Appleton-Century-Crofts, 1980: $587-601$.

(3) See reference (2): 588.

(4) Hern W A. Abortion practice. Philadelphia: J BD Lippincott, 1984: 289

(5) Warren M A. On the moral and legal status of abortion. $\bar{N}$ In: Feinburg J, ed. The problem of abortion. (2nd ed). Belmont, CA: Wadsworth, 1984: 102-119.

(6) Roberts C J, Lowe C R. Where have all the conceptions gone? Lancet 1975: 1:498-499.

(7) O'Donnell T J. Medicine and Christian morality. New York: Alba House, 1976: 194-195.

(8) See reference (7): 197

(9) See reference (7): 196

(10) O'Donnell T J. Abortion II (moral aspect). In: The new Catholic encyclopedia. Vol 1. New York: McGraw-Hill, 1976: 29.

(11) See reference (2): 594-595. 